\title{
Extraction and Characterization of Fibres from the Stalk and Spikelets of Empty Fruit Bunch
}

\author{
Yakum Reneta Nafu, ${ }^{1,2}$ Josepha Foba-Tendo, ${ }^{3}$ Ebenezer Njeugna, \\ Gossett Oliver, ${ }^{4}$ and Kavian Omar Cooke ${ }^{4}$ \\ ${ }^{1}$ Department of Mechanical Engineering, Higher Technical Teachers' Training College, The University of Bamenda, \\ P.O. Box 34, Bambili, Cameroon \\ ${ }^{2}$ Department of Mechanical Engineering, Ecole Normale Superieur d' Enseignement Technique (ENSET), \\ University of Douala, Douala, Cameroon \\ ${ }^{3}$ Department of Chemistry, Faculty of Science, University of Buea, Buea, Cameroon \\ ${ }^{4}$ School of Engineering, University of Technology, Kingston, Jamaica \\ Correspondence should be addressed to Josepha Foba-Tendo; jnfoba@gmail.com
}

Received 19 March 2015; Revised 18 May 2015; Accepted 27 May 2015

Academic Editor: Parsotam H. Parsania

Copyright ( 2015 Yakum Reneta Nafu et al. This is an open access article distributed under the Creative Commons Attribution License, which permits unrestricted use, distribution, and reproduction in any medium, provided the original work is properly cited.

Fibres from different parts of empty fruit bunch, which is a major solid waste from oil palm processing, were subjected to different pretreatments and characterised for variability in length and diameter, mechanical performance, and proximate and trace element composition. Morphology and surface composition of the fibres were determined using scanning electron microscopy with energy dispersive X-ray. The fibres were further treated with $\mathrm{KOH}$-boric acid and characterized by Fourier transform infrared spectroscopy, $\mathrm{X}$-ray diffraction, and scanning electron microscopy. Fibre yield was higher for spikelet than stalk. Fibres from stalk were generally larger in diameter and showed significant differences in potassium and galacturonic acid content, strength, and rigidity. Scanning electron microscopy confirmed the widespread occurrence of silica bodies as well as significant differences in the microstructure of stalk and spikelet fibres. Stalk fibres showed a greater level of porosity than spikelet fibres in the section perpendicular to the major axis. The morphology of $\mathrm{KOH}$-boric acid treated fibres suggested higher recalcitrance of spikelet fibres. The significant differences between fibres from stalk and spikelet suggest that EFB, used as feedstock for biobased industries, requires more systematic characterization and separation into stalk and spikelet, which may lead to a more judicious exploitation of this valuable waste.

\section{Introduction}

The sustainable exploitation and development of resources and materials is one approach to ensuring sustainable technologies. Biobased industries are receiving increased interest as one response to sustainability issues associated with the exploitation of nonrenewable resources. The effectiveness of this response, however, depends on the judicious use of biomass as feedstock for chemical industries, biomaterials, and bioenergy. The cultivation of crops for biomass has gained commercial status, but there is stiff competition on arable land for food production due to a rapidly increasing world population. This has led to increased interest in agricultural waste, which is abundant and cheap, as a renewable feedstock [1]. The cultivation and processing of important cash crops such as cocoa, cotton, rice, and oil palm generate large quantities of agricultural waste which presents disposal problems but is increasingly regarded as a resource for biobased industries.

Palm oil is produced in many tropical countries, notably in Africa and Asia, and it is the largest global source of edible oil. It constitutes 38.5 million tons or $25 \%$ of world's total oil and fat production [2]. Cameroon, a West African country, produces 3.5 tons of oil/ha/year [3]. Waste from oil palm cultivation and palm oil processing include empty 
fruit bunches (EFB), shell, palm kernel, sludge, palm oil mill effluent (POME), fronds, and trunk [4].

EFB is a highly fibrous, mineral rich material $[5,6]$ and is one of the most important solid waste fractions from the oil mill [7]. The EFB is $23 \%$ of the weight of a fresh fruit bunch and an oil mill with a capacity of $60 \mathrm{t}$ of fruit bunches per hour produces more than $54,000 \mathrm{t}$ of empty fruit bunches per year [8]. EFB has low commercial value and poses a disposal problem due to its bulky nature. Conventionally, it is burnt, disposed of in landfills, or composted to organic fertilizer [9]. The burning of EFB is, however, no longer recommended as it causes air pollution. There is therefore the need to optimize the use of EFB so as to solve these problems and enhance its judicious us as feedstock for valuable products in the chemical, energy, and biomaterials sectors.

Current uses of EFB from large and medium-scale industrial units include recycling for nutrients and moisture control in farms, fuel, mushroom cultivation, biogas production, cellulose, and fibre extraction. Fibres from EFB have found applications in the production of composites, textiles, cellulose, and paper [10]. Interest in biofibres has grown as they are increasingly viewed as a green alternative to the more conventional fibre reinforcements such as glass fibres [11]. The composition and fibrous character of EFB determines its various applications such as recycling for nutrients and moisture control in farms, fuel, mushroom cultivation substrate, biogas production, cellulose, and fibre extraction. In addition to its high mineral content, EFB is also rich in holocellulose (82.4\% of extractives-free organic fraction) and lignin (17.6\% of extractives-free organic fraction) [10]. Lignin, cellulose, and hemicellulose contents are variable, but comparable to soft and hardwoods, indicating a potential for pulping and use as raw material in biorefineries [10]. The pretreatment of EFB fibres using merely water, acid, and alkali increases sugar production and high removal of hemicellulose and/or lignin in the fibres [12].

Palm oil production is carried out in two types of facilities, distinguished by the scale of operations and processes/technologies used $[13,14]$. Generally, processing units handling up to 2 tons of fresh fruit bunches per hour are considered to be small-scale, while large-scale mills are able to process more than 10 tons per hour. Large plantations operate modern industrial mills where the full fruit bunches are steam-sterilized before the nuts are extracted mechanically using a hammer mill. The oil is subsequently pressed out, separated and purified [15]. The global palm oil market is dominated by these operators, but artisanal producers in West and Central Africa still contribute a significant proportion of the production $[13,14]$. Smallholders who process their own fruit operate small, usually manuallyintensive mills, where the nuts are extracted from bunches before cooking. In some traditional practices, the fruitcontaining spikelets are separated from the stalk before the fruit is extracted. The spikelet is subsequently used as fuel while the stalk is scattered in gardens or simply discarded. The full fruit bunches do not undergo steam treatment as is the case in modern mills [16]. Data available on the chemical composition and other fibre characteristics make no difference between the spikelet and the stalk [17-19]. The fresh fruit observed growing directly on the spikelet supports the structural development as spikelets and not separate rachises [20].

However, the observation on artisanal oil production in some parts of Cameroon where the spikelet is separated from stalk before fruit extraction has prompted a more systematic characterization of EFB spikelet and stalk. The fibres of spikelet are higher in dry weight than those of the stalk from EFB of the oil palm. This alternative is expected to lead to reductions in steam requirements for sterilization and thus presents the potential for more sustainable operations. It might be more labour-intensive, but Nkongho et al. [13] make a case for more labour-intensive artisanal processing methods in a context of high unemployment. This paper presents results of investigations of the physical characteristics, chemical composition, tensile strength, microstructure, and response to alkali treatment of fibrous biomass from EFB stalk and spikelet from 2 types of palm oil production facilities in Cameroon.

\section{Materials and Methods}

Empty fruit bunches were obtained from an industrial operator, Cameroon Development corporation (C.D.C.) (Mondoni and Idenua Mills), and a small-scale operator in Muyuka, all located in Fako Division of the South West Region of Cameroon.

The empty fruit bunches were separated manually into stalk and spikelet and then shredded. The stalks were defibred in one pass through a screw-type shredder fitted with and 7.5 horsepower motor while the spikelets required three passes. Proximate composition of fibres was determined and the fibres were then cleaned with mild dilute alkali ( $2 \mathrm{wt} \%)$ before characterization for length, diameter, and tensile strength. The fibres were further subjected to alkali delignification and then characterized for morphology and chemical composition. Techniques used included standard wet chemical methods, scanning electronic microscopy (SEM) with Energy dispersive X-ray (EDX), XRD, and tensile testing.

\subsection{Shredding, Cleaning, and Strong Alkali Treatment of EFB} Fibres. Fibre yield was determined on stalk and spikelet from 10 bunches. Samples for strong alkali treatment were oven dried at $100^{\circ} \mathrm{C}$ for $24 \mathrm{hrs}$ and ground in a domestic blender. The ground fibre was sieved and fibres of particle size less than 35 mesh were subjected to pretreatment with $5 \% \mathrm{NaOH}$ with boiling for $2 \mathrm{hrs}$, followed by treatment with the $10 \% \mathrm{NaOH}$ at $20^{\circ} \mathrm{C}$ for $16 \mathrm{hrs}$ prior to strong alkali treatment. This consisted of treating samples with $24 \% \mathrm{KOH}-2 \% \mathrm{H}_{3} \mathrm{BO}_{3}$ (boric acid) at $20^{\circ} \mathrm{C}$ for $2 \mathrm{hrs}$. The slurry obtained after $\mathrm{KOH}$ treatment was filtered and the residues collected and washed several times with distilled water in order to remove impurities. The product was oven dried at $50^{\circ} \mathrm{C}$ for $8 \mathrm{hrs}$ and samples taken for XRD, FT-IR, and TGA analyses.

2.2. Galacturonic Acid Content. The galacturonic acid content was determined by colorimetry using a modified $\mathrm{m}$ hydroxydiphenyl sulphuric acid method [21]. Standards were 


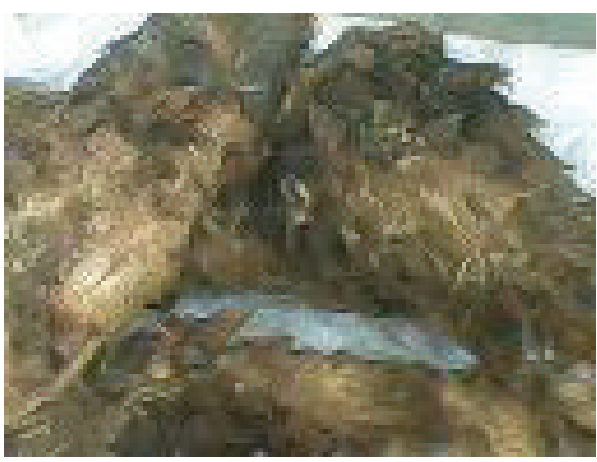

(a)

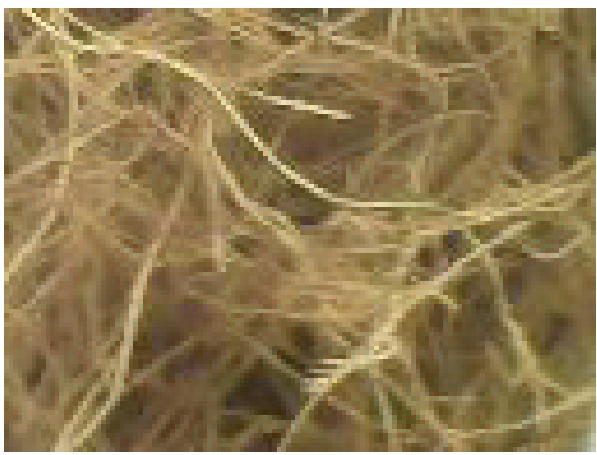

(c)

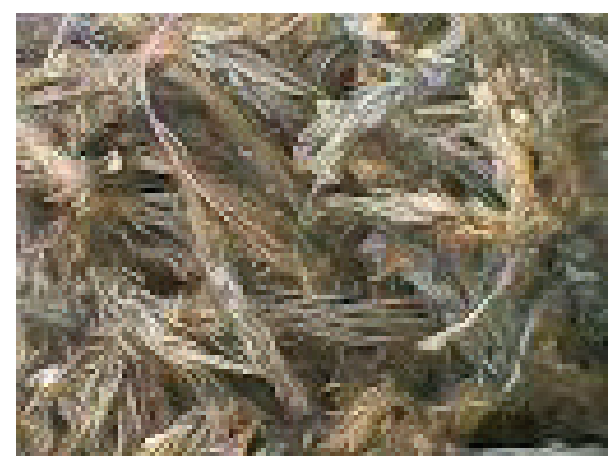

(b)

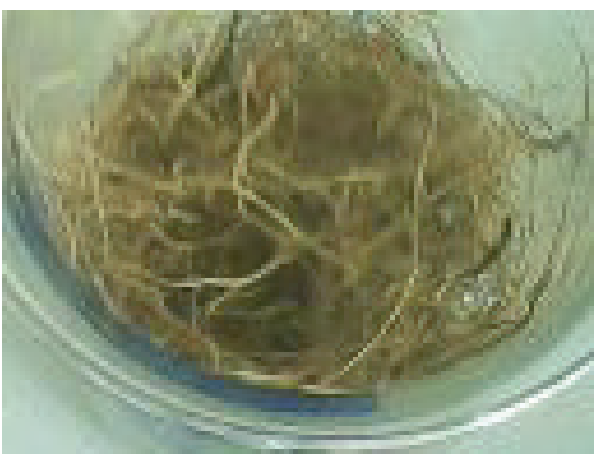

(d)

Figure 1: (a) Stalk of EFB, (b) spikelet of EFB, (c) fibres of stalk, and (d) fibres of spikelet.

prepared using galacturonic acid at concentrations of 29100 microgram per millilitre. This determination was done in triplicates.

2.3. Determination of Tensile Strength. Tensile strength test was conducted in the mechanical laboratory of ENSET Douala, Cameroon, using a modified fibre traction device designed by Rodrigue (2008) [22] for testing filaments of raffia.

2.4. Proximate Analysis. Basic cations $\mathrm{Ca}, \mathrm{Mg}$, and $\mathrm{K}$ are extracted by dry ashing in a muffle furnace at $500^{\circ} \mathrm{C}$, diluted using a dilute acid mix of $\mathrm{HCl} / \mathrm{HNO}_{3}$, and analyzed using the atomic absorption spectrophotometer [23] and reported as a \%. Total $\mathrm{N}$ was determined from a wet acid digest [24] by colorimetric analysis [25]. All determinations were carried out on extractives-free samples.

2.5. Scanning Electron Microscopy (SEM). The surface morphology of samples was examined by a Scanning Electron Microscope (SEM) (JEOL JSM-5600 or TESCAN VEGA III XMU, Q150 TE). Prior to examination, samples were prepared by mounting about $0.5 \mathrm{mg}$ of powder onto a $5 \mathrm{~mm}$ $\times 5 \mathrm{~mm}$ double sided carbon tape, on an aluminum stub. The powder was then sputter-coated for 40 seconds with carbon or gold.

2.6. X-Ray Diffraction. The XRD diffractograms of the precursors and the decomposition products were recorded on a Bruker D8 Advance X-ray diffractometer using a $\mathrm{Cu} \mathrm{K} \alpha$ radiation source $(\lambda=0.15406 \mathrm{~nm}, 40 \mathrm{kV}$, and $40 \mathrm{~mA})$. Scans were taken over the $2 \theta$ range from $10^{\circ}$ to $100^{\circ}$ in steps of $0.01^{\circ}$ at room temperature in open quartz sample holders.

2.7. FTIR. FT-IR spectra were recorded from 4000 to $400 \mathrm{~cm}^{-1}$ on a PerkinElmer Spectrum Two universal attenuated total reflectance Fourier transform infrared (UATR-FTIR) spectrometer.

\section{Results and Discussion}

3.1. Physical Properties. The percentages of fibres in the stalk and spikelet of EFB dry weight were in the ranges of $20-32 \%$ and $68-80 \%$, respectively. Figures $1(\mathrm{a})$ and 1 (b) represent the stalk and the spikelet of EFB after manual separation using a cutlass and their fibres, while Figures 1(c) and 1(d) show that spikelets yield more fibre per EFB than stalk.

The dry weight results of the stalk and spikelet of 10 different EFBs are presented in Figure 2.

The quantities of fibres from the histogram show that the stalk and spikelet were 20 to $32 \%$ and 68 to $80 \%$ dry weight, respectively. The result indicates that there are more fibres in the spikelet than in the stalk from EFB of the oil palm tree.

The diameter of EFB fibres (Table 1) showed important variability along the length.

The fibres from the stalk were bigger than those from the spikelet. The length of stalk and spikelet varied from $10 \mathrm{~mm}$ to $105 \mathrm{~mm}$ and $80 \mathrm{~mm}$ to $368 \mathrm{~mm}$ giving an average 


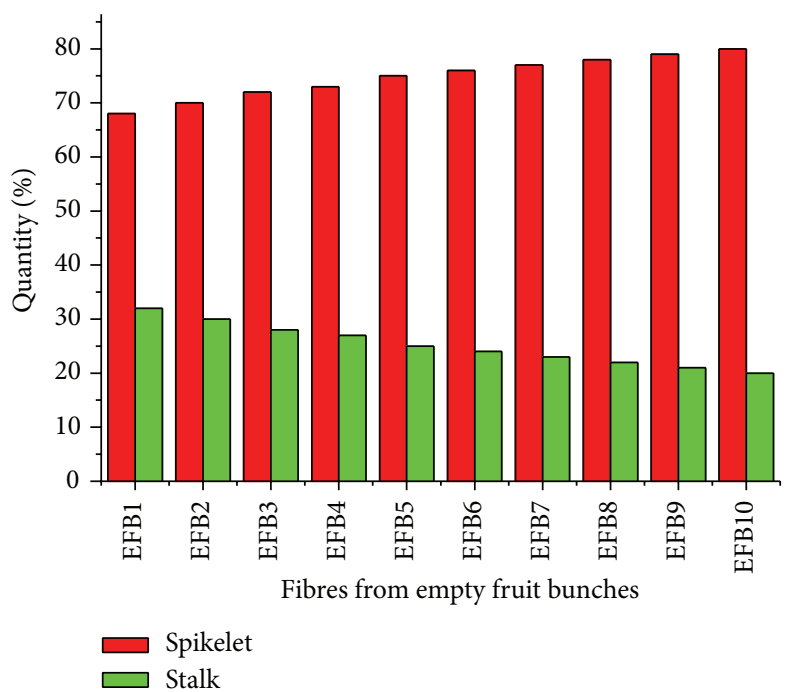

FIGURE 2: Histogram of stalk and spikelet \% from EFB from Mondoni Oil Mill.

TABLE 1: Diameters of fibres from stalk and spikelet compared to other studies.

\begin{tabular}{lcc}
\hline Parts & Diameter $(\mu \mathrm{m})$ & Reference \\
\hline EFB & $150-500$ & {$[1]$} \\
EFB & $150-500$ & {$[17]$} \\
EFB & $250-610$ & {$[26]$} \\
Stalk of EFB & $200-715$ & Present study \\
Spikelet of EFB & $150-650$ & Present study \\
\hline
\end{tabular}

of $30 \mathrm{~mm}$ and $140 \mathrm{~mm}$, respectively. The average fibre lengths are comparable to values for fibres from other studies where the fibres were separated manually.

The mild alkali treatment with dilute $\mathrm{NaOH}$ was intended to remove mostly oils, some lignin, and a limited amount of acidic hemicelluloses from the fibre surface.

Hemicelluloses are a highly heterogeneous group of structural polysaccharides which are found very closely associated with cellulose and lignin in the plant cell wall, thus making their extraction difficult. Several studies have found that the use of alkali $(\mathrm{NaOH}, \mathrm{LiOH}$, or $\mathrm{KOH})$ together with boric acid additions significantly enhances the release of hemicelluloses $[27,28]$. The enhanced release is attributed to the ability of the hydroxyl and borate ions to form plyanions with the hemicelluloses, as well as the ability of the alkali to cause swelling of the crystalline cellulose. The polyanions may be carboxylates, borate complexes of some hemicelluloses and alcoholates. The $\mathrm{KOH} /$ Boric acid mixture represents a relatively milder but more effective extractant for releasing hemicelluloses within the cell walls at high alkali concentrations and without mercerization.

3.2. Galacturonic Acid Content. Galacturonic acid content was higher in stalk than the spikelet of EFB crude extract. Also more galacturonic acid was released at higher sodium hydroxide concentration.

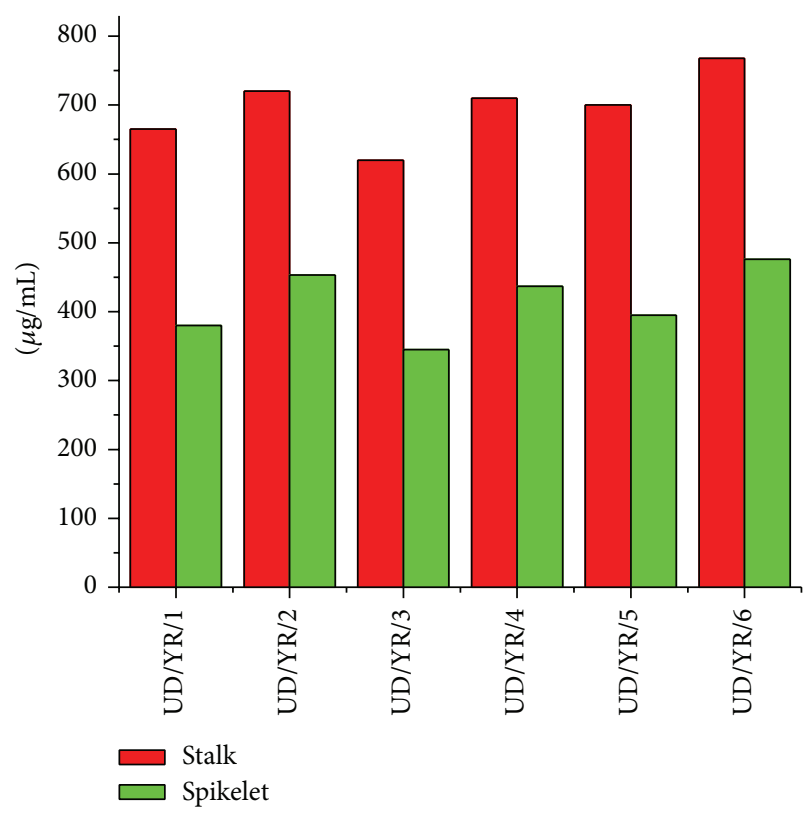

FIGURE 3: Histogram of galacturonic acid content.

TABLE 2: Pretreatment of EFB fibres.

\begin{tabular}{lccc}
\hline $\mathrm{S} / \mathrm{N}$ & $\mathrm{Code}$ & $\%$ of $\mathrm{NaOH}$ & Temperature \\
\hline 1 & $\mathrm{UD} / \mathrm{YR} / 1$ & 0 & Room temp. \\
2 & $\mathrm{UD} / \mathrm{YR} / 2$ & 0 & $100^{\circ} \mathrm{C}$ \\
3 & $\mathrm{UD} / \mathrm{YR} / 3$ & 1 & Room temp. \\
4 & $\mathrm{UD} / \mathrm{YR} / 4$ & 1 & $100^{\circ} \mathrm{C}$ \\
5 & $\mathrm{UD} / \mathrm{YR} / 5$ & 2 & Room temp. \\
6 & $\mathrm{UD} / \mathrm{YR} / 6$ & 2 & $100^{\circ} \mathrm{C}$ \\
\hline
\end{tabular}

Galacturonic acid content of the different EFB extract is presented in the histogram in Figure 3.

The EFB crude extracts were coded using the following pretreatment conditions as indicated on Table 2 .

The higher galacturonic acid content correlates with higher cation content; notably, $\mathrm{K}^{+}$and is also a reflection of differences in content of noncellulosic polysaccharides. This difference might explain the differences in response of the fibres to alkali treatments as well as mechanical properties of the fibres. The results also suggest differences in water absorptivity. Ramadevi et al. [29] found that alkalization of abaca fibres which leads to a reduction in hemicelluloses content resulted in a reduction in water adsorption.

3.3. Mechanical Properties. Fibres from spikelets of EFB showed higher strength than those of the stalk of EFB while the extension at failure of the fibre from the stalk was higher than that of the fibre from the spikelet (Table 3).

Fibres from spikelets of EFB have higher strength than those of the stalk of EFB while the extension at failure of the fibre from the stalk is more than that of the fibre from the spikelet. 
TABLE 3: Mechanical properties of fibres from stalk and spikelet.

\begin{tabular}{|c|c|c|c|c|}
\hline & Tensile strength $(\mathrm{MPa})$ & Young's modulus (MPa) & Elongation at break (\%) & Source \\
\hline$\overline{E F B}$ & 71 & 1703 & 11 & {$[26]$} \\
\hline EFB & $100-400$ & $1000-9000$ & $8-11$ & {$[18]$} \\
\hline $\mathrm{EFB}$ & $100-400$ & $1000-9000$ & $8-11$ & [17] \\
\hline Stalk of EFB & $51.73-82.40$ & $947-1859$ & $9.5-12.15$ & Present study \\
\hline Spikelet of EFB & $93.13-135.8$ & $2324-3563$ & $7.92-11.05$ & Present study \\
\hline
\end{tabular}

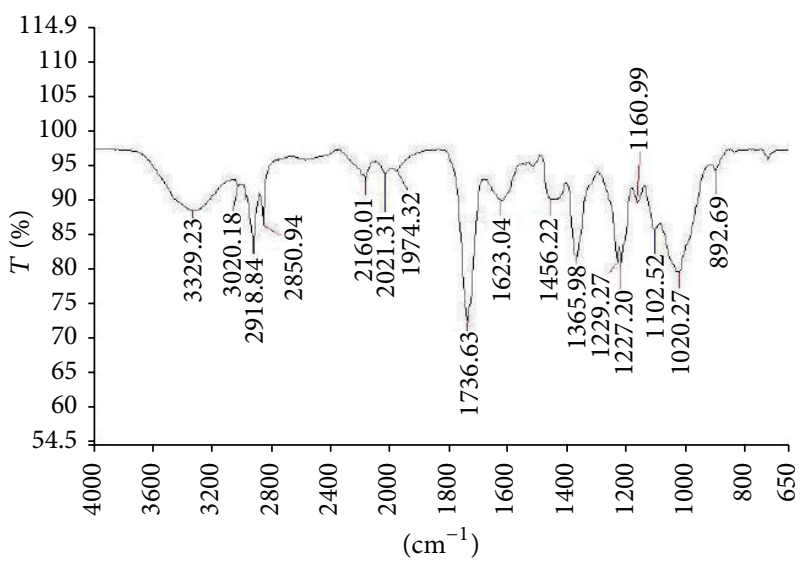

(a)

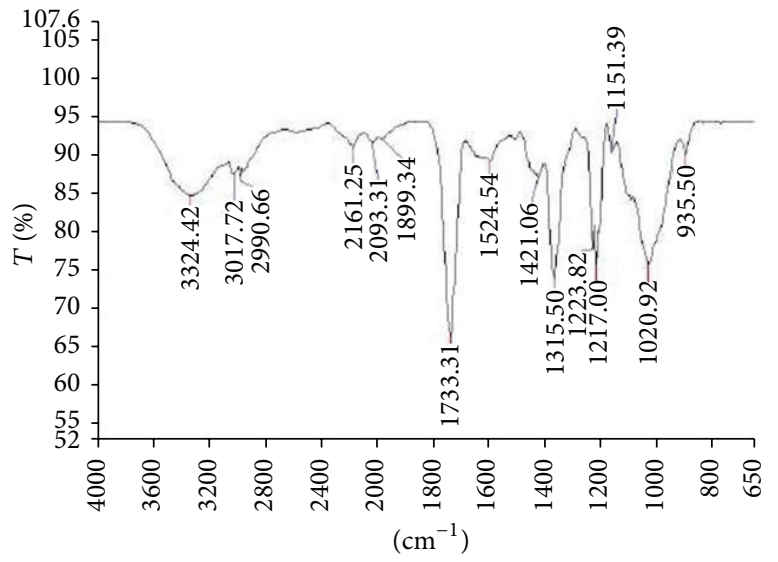

(b)

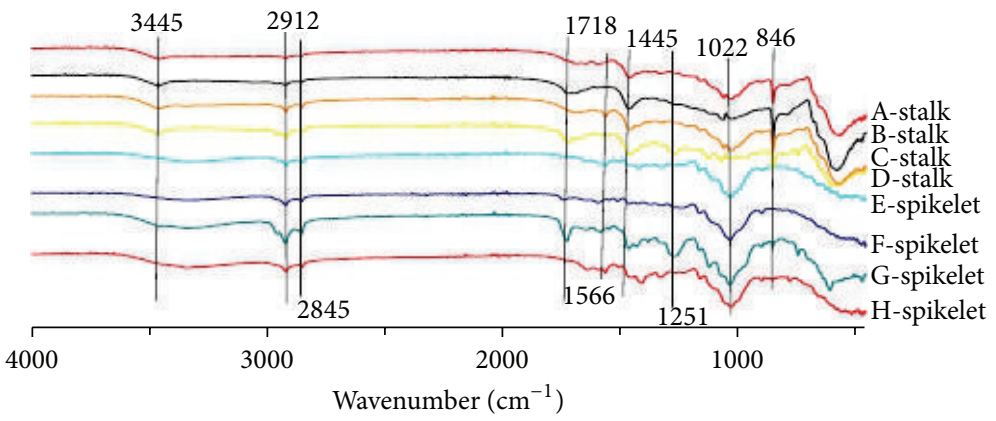

(c)

FIGURE 4: (a) FTIR of stalk fibre after acetone dewaxing. (b) FTIR of spikelet fibres after acetone dewaxing. (c) FTIR spectra of stalk and spikelet fibres after $\mathrm{KOH}$-Boric acid treatment.

3.4. Chemical Composition. The results showed some differences in chemical composition of fibres from stalk and spikelet with the most significant differences recorded in the ash and potassium content (Table 4). Sodium levels are considerably higher in EFB from the plantation closer to the sea (Bakingili), reflecting the importance of soils/environment.

The difference in ash content may be due to different cultivation and production area of oil palm in Fako Division.

3.5. FTIR Analyses. FTIR spectra of fibres dewaxed with acetone (Figures 4(a) and 4(b)) and after delignification (Figure 4(c)) do not show significant differences between spikelet and stalk. Absorption peaks at $3600 \mathrm{~cm}^{-1}-3000 \mathrm{~cm}^{-1}$ (strong and broad) for both stalk and spikelet fibres are assigned to the hydroxyl group, present in cellulose, lignin, and hemicelluloses [30]. The absorption bands located at
TABLE 4: Ash content and major element composition of stalk and spikelet from 2 locations in Fako Division.

\begin{tabular}{lcccccccc}
\hline Part of EFB Location & ASh & $\mathrm{Ca}$ & $\mathrm{K}$ & $\mathrm{Mg}$ & $\mathrm{N}$ & $\mathrm{Na}$ & $\mathrm{P}$ \\
\hline \multirow{2}{*}{ Stalk } & Bakingili & 10.58 & 0.31 & 4.03 & 0.13 & 0.65 & 0.05 & 0.05 \\
& Mondoni & $\mathrm{NA}$ & 0.09 & 3.31 & 0.14 & 0.44 & 0.004 & 0.09 \\
\hline \multirow{2}{*}{ Spikelet } & Bakingili & 7.07 & 0.09 & 1.75 & 0.14 & 0.63 & 0.03 & 0.05 \\
& Mondoni & $\mathrm{NA}$ & 0.22 & 1.78 & 0.14 & 0.43 & 0.001 & 0.09 \\
\hline
\end{tabular}

$2912 \mathrm{~cm}^{-1}$ and $2834 \mathrm{~cm}^{-1}$ are assigned to the stretching hydrogen vibrations of $\mathrm{C}-\mathrm{H}$ group $[31,32]$. The peak observed at $1718 \mathrm{~cm}^{-1}$ can be attributed to the $\mathrm{C}=\mathrm{O}$ stretching in the acetyl and uronic ester groups of hemicelluloses and the $\mathrm{p}$ coumaric units of the lignin [33]. The important bands used to identify the cellulose are bands at $1445 \mathrm{~cm}^{-1}$ and $1414 \mathrm{~cm}^{-1}$ 


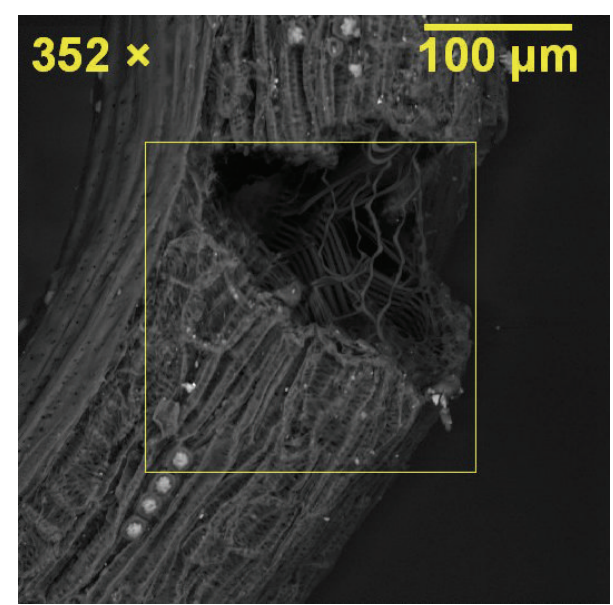

(a)

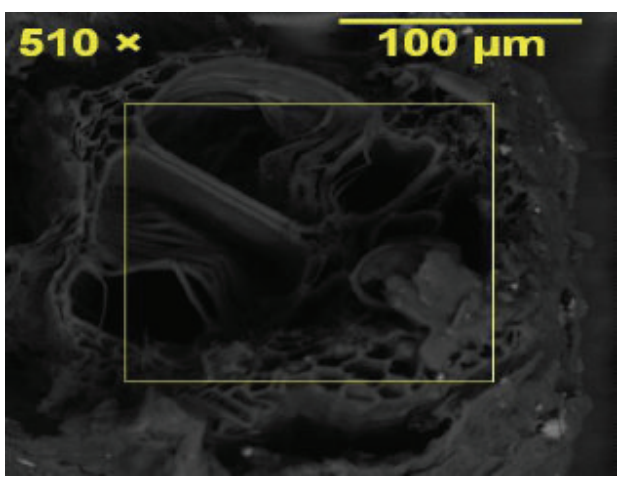

(c)

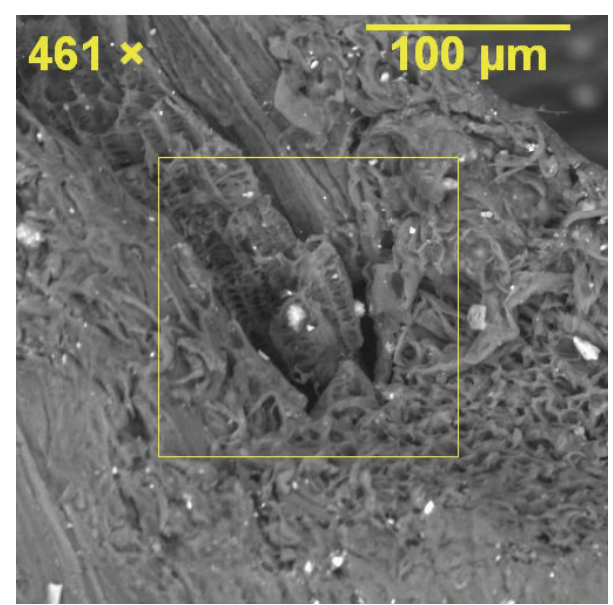

(b)

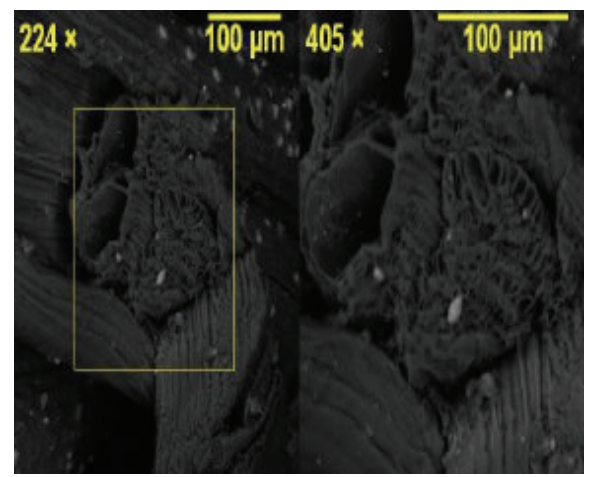

(d)

Figure 5: (a) SEM of fracture of fibre from spikelet of EFB. (b) SEM of cross-sectional area of fibre from spikelet of EFB. (c) SEM of cross section of fibre from stalk of EFB. (d) SEM of fracture of fibre from stalk of EFB.

[34], whilst bands at $1566 \mathrm{~cm}^{-1}$ and $1251 \mathrm{~cm}^{-1}$ are attributed to the aromatic skeletal structure of lignin [35]. The Glycosidic $\mathrm{C}-\mathrm{O}-\mathrm{C}$ band occurred at $1022 \mathrm{~cm}^{-1}$.

FTIR of delignified fibres (Figure 4(c)) showed almost complete elimination of the intensity of the bands at $1718 \mathrm{~cm}^{-1}$ and the absence of the band at $1556 \mathrm{~cm}^{-1}$, indicating significant elimination of hemicelluloses and lignin [36]. There is however evidence of residual ligin (band at $1251 \mathrm{~cm}^{-1}$ ) and hemicellolose (band at $1718 \mathrm{~cm}^{-1}$ ) in both samples.

3.6. Morphological Analysis. SEM micrographs of fibres cleaned with dilute alkali and after $\mathrm{KOH}$-Boric acid delignification treatments are shown in Figures 5, 6, and 7. Figure 5 shows the SEM of fracture and cross-sectional area of fibres from stalk and spikelets. Figure 5(a) reveals the arrangement of fibrils in helical spirals. These micrographs also reveal the widespread occurrence of silica bodies that have previously been reported by other workers [37]. Figures 5(b), 5(c), and 5(d) show important differences in the density and porosity across sections of spikelet (Figure 5(b)) and stalk (Figures 5(c) and 5(d)). Spikelet fibres appear more compact than stalk fibres.
SEM of alkali-delignified fibres reveal remnants of fibril bundles in spiklet fibres and a more extensive degradation of the fibril bundle structure in stalk fibres. SEM micrograph of delignified stalk reveals sheets which are most probably highly crystalline cellulose sheets obtained by chain folding [38]. This difference in response suggests that spikelet fibrous biomass is more recalcitrant to pretreatments than stalk fibrous biomass.

3.7. SEM/EDX Analysis. SEM of the surfaces of spikelet fibres treated with hot water $\left(100^{\circ} \mathrm{C}\right)$ only and $2 \% \mathrm{NaOH}$ at $25^{\circ} \mathrm{C}$ are shown in Figure 7. The micrographs reveal silica bodies spread uniformly over the fibre surface. Figure 5(b) shows that sodium hydroxide treatment removes most of the silica bodies from the surface.

EDX spectra are presented in Figures 8(a), 8(b), 8(c) and $8(\mathrm{~d})$ for selected stalk and spikelet fibres subjected to different treatments. These reveal that the mineral content is largely due to the presence of potassium, silicon, calcium magnesium, and aluminum and that the enrichment in these elements is closely associated with the silica bodies. 


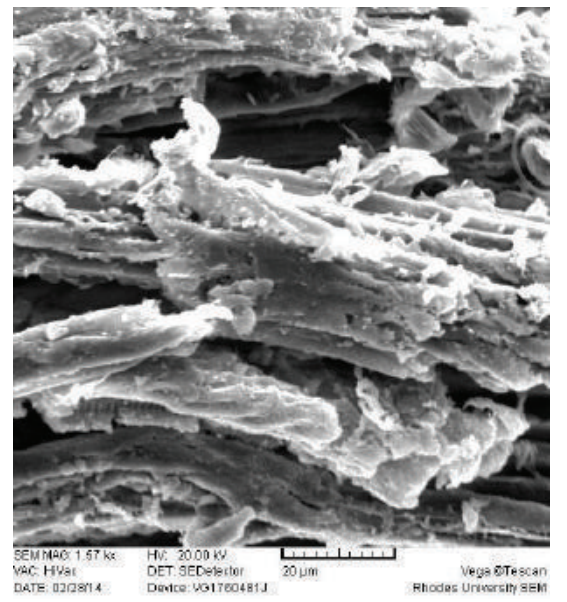

(a)

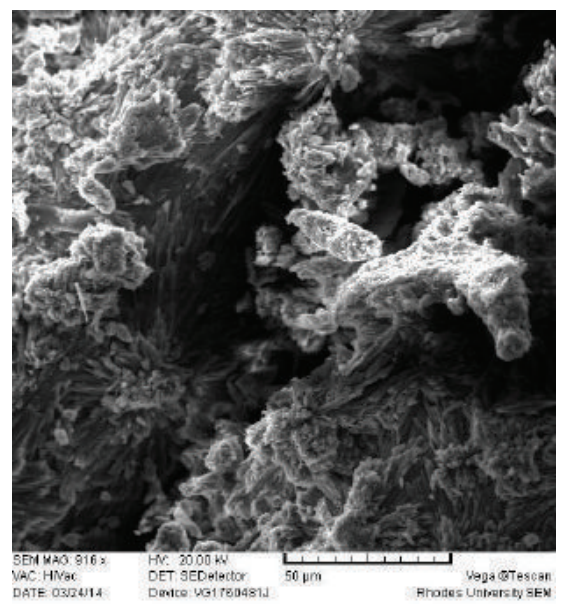

(c)

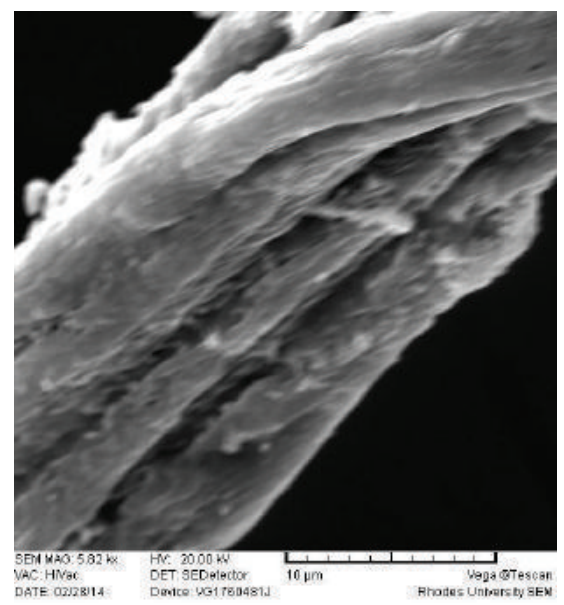

(b)

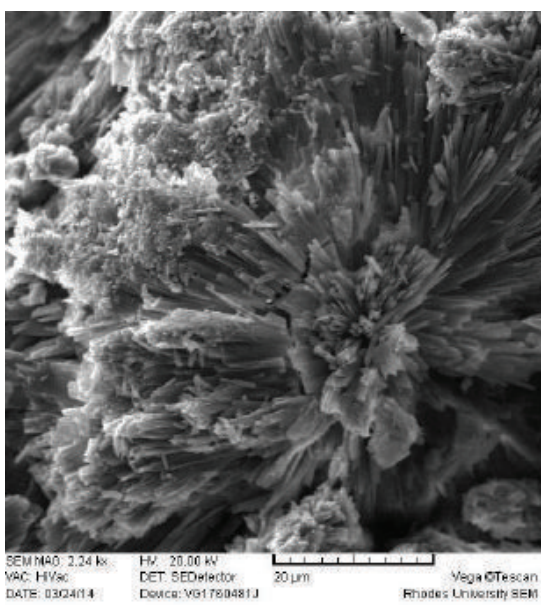

(d)

FIGURE 6: SEM of fibres ((a) and (b) spikelet; (c) and (d) stalk) after strong alkali delignification.

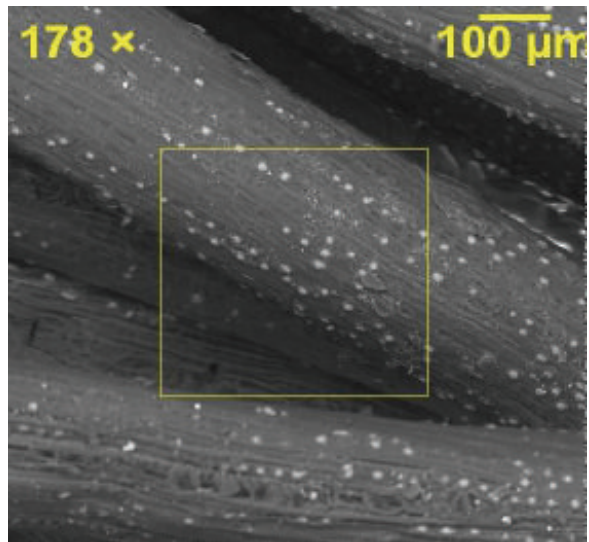

(a)

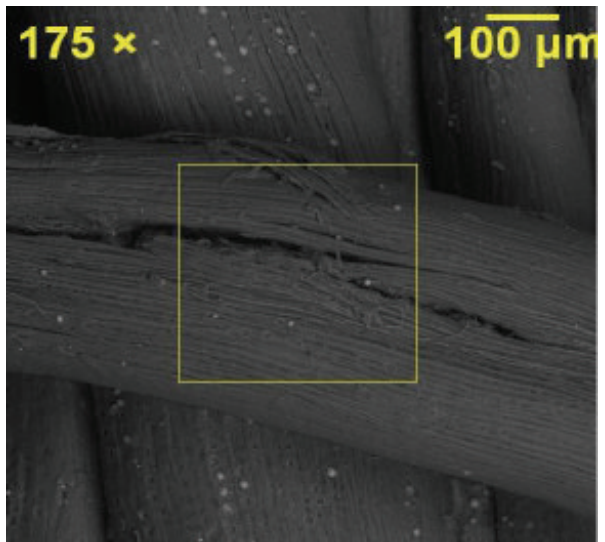

(b)

Figure 7: (a) SEM of Spikelet fibre treated with $0 \% \mathrm{NaOH}$. (b) SEM of spikelet fibre treated with $2 \% \mathrm{NaOH}$. 

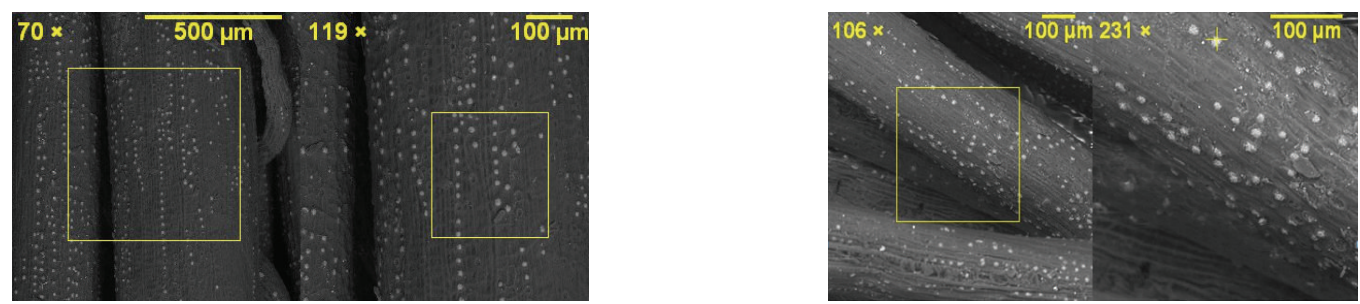

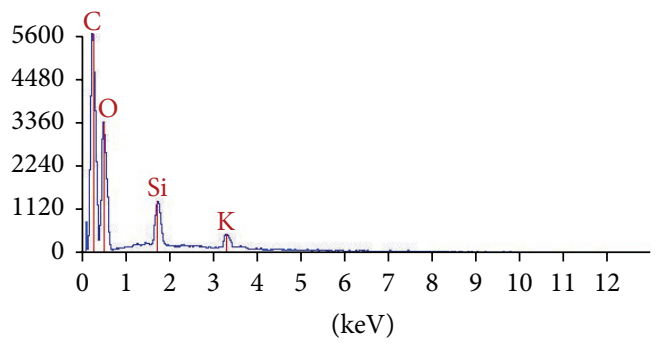

(a)
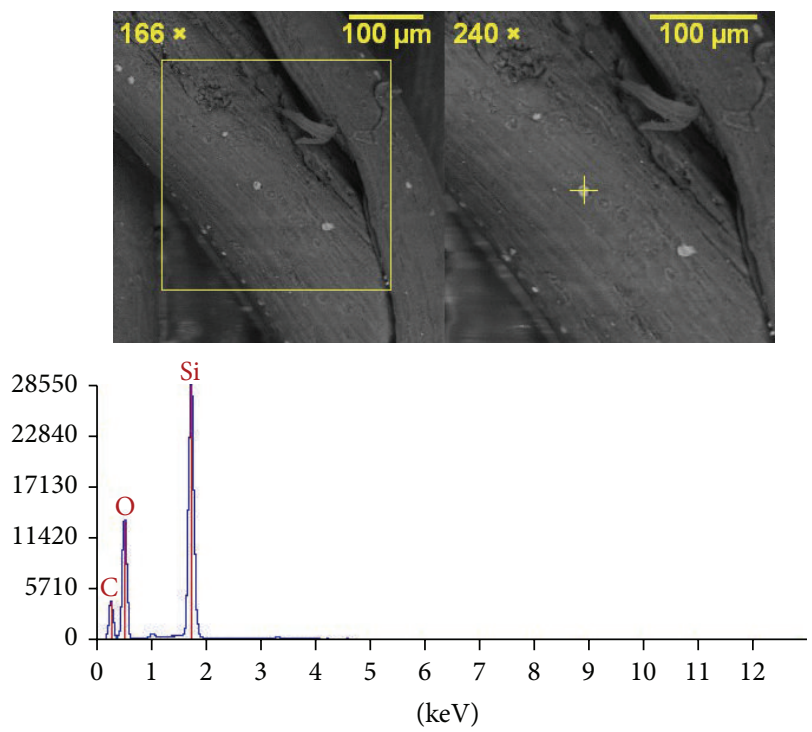

(c)

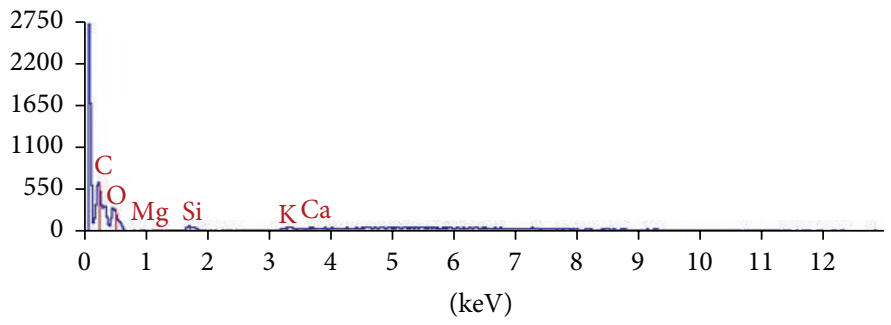

(b)
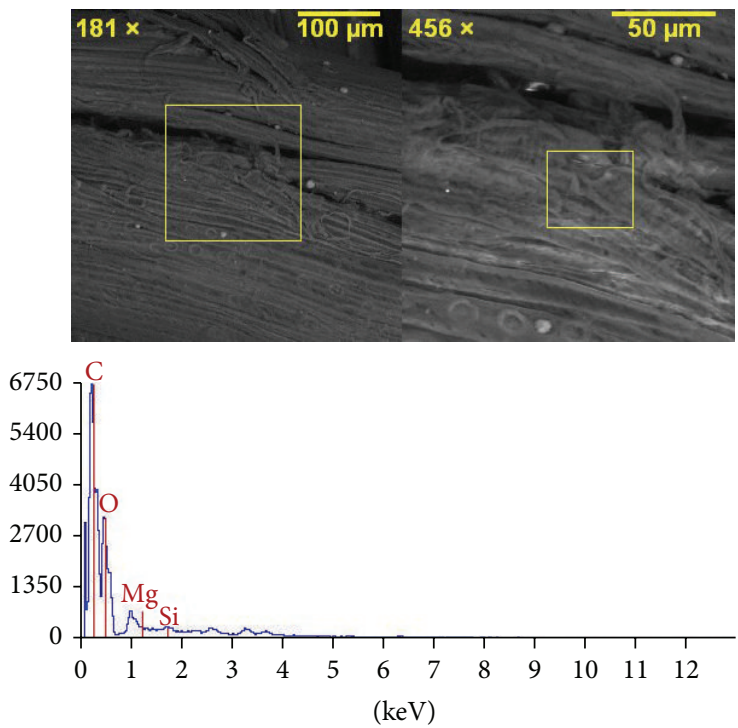

(d)

FIGURE 8: (a) SEM/EDX of $0 \% \mathrm{NaOH}$ treated stalk. (b) SEM/EDX of $0 \% \mathrm{NaOH}$ treated spikelet. (c) SEM/EDX of $2 \% \mathrm{NaOH}$ treated stalk. (d) SEM/EDX of $2 \% \mathrm{NaOH}$ treated spikelet.

3.8. X-Ray Diffraction (XRD). The X-ray diffraction of the stalk and spikelet is shown in Figure 9. XRD data was collected for four different samples of treated stalk and spikelet fibres. Both stalk and spikelet-derived material shows a very broad peak at about $17^{\circ}$ and a relatively strong and sharp peak at $22.1^{\circ}$. The broad peak at $2 \theta$ angle $17^{\circ}$ is probably due to amorphous cellulose or the overlapping of the (101) and reflections [39], while the peak at $2 \theta$ of $22.1^{\circ}$ is assigned to the strong (200) reflection of cellulose [36, 40-42]. The diffractogram of spikelet-derived cellulose shows additional sharp peaks, including one at $2 \theta$ reflection angle of $35^{\circ}$. The latter has been assigned to the (040) reflections of cellulose. This peak appears to be present in the diffractogram of the stalk-derived cellulose, but it is considerably broadened and weaker. This suggests a higher level of transformation of the stalk biomass following the strong alkali treatment.

\section{Conclusion}

Fibres from stalk and spikelet of EFB were pretreated and studied using different techniques. The dry weight percentages of fibre from stalk and spikelet of EFB and their diameters were in the ranges $20-32 \%, 68-80 \%$ and $200-$ $715 \mu \mathrm{m}, 150-650 \mu \mathrm{m}$, respectively. The diameters varied along the length of the fibre. Stalk fibres were richer in potassium, which is the major plant nutrient. The SEM clearly showed silica bodies found in craters on the surface of the fibres. The cross section area showed irregular porosity and significant differences between the porosities of fibres from stalk and spikelet. Spikelet fibres were shown to be stronger and the results from SEM and XRD characterization of alkali-treated material show that spikelet fibres undergo less transformation than stalk fibres. The ease of transformation of biomass to 


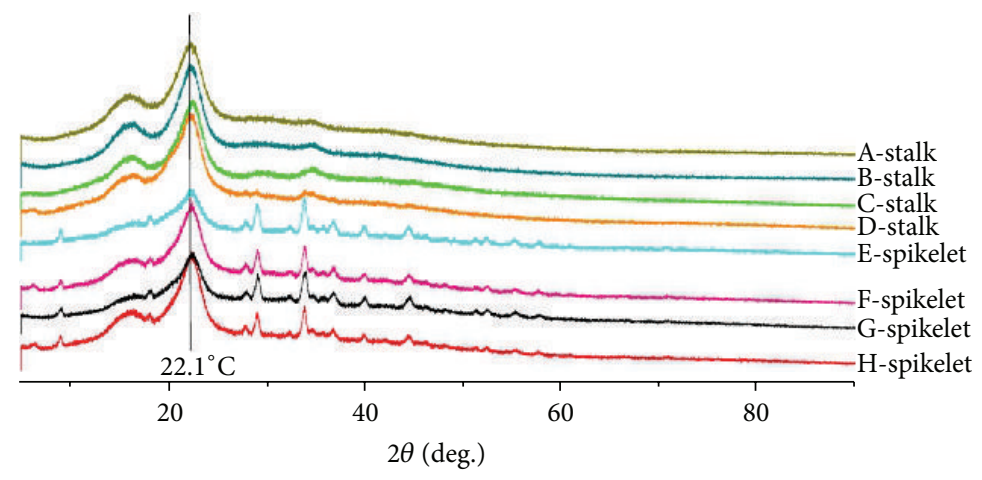

FIgURE 9: XRD of fibre from stalk and spikelet of EFB.

bioenergy using sustainable pretreatment technologies is a key step in biorefineries. Based on composition and response to treatment, the stalk fibres show more promise as feedstock for nutrient recycling or bioenergy due to their significantly higher potassium contents and lower recalcitrance. The spikelet fibres look more interesting for use as reinforcing fibres due to their higher strengths and recalcitrance. These results suggest that there is potential for improving sustainability through the adoption of more appropriate processing of full fruit bunches (FFBs) for the extraction of palm nuts for palm oil production where spikelet and stalk are separated prior to fruit extraction.

\section{Conflict of Interests}

The authors declare that there is no conflict of interests regarding the publication of this paper.

\section{Acknowledgments}

The authors would like to thank the University of Technology, Jamaica, and University of Buea, Cameroon, where most of the experimental works were performed. The authors are equally grateful to Rhodes University, South Africa, for providing assistance with FTIR analysis and some of the scanning electron microscopy work.

\section{References}

[1] H. P. S. A. Khalil, H. M. Fizree, M. Jawaid, and O. S. Alattas, "Preparation and characterization of nano structured materials from oil palm ash: a bio-agricultural waste from oil palm mill," Bioresources, vol. 6, no. 4, pp. 4537-4546, 2011.

[2] M. P. O. C. (MPOC), World's Oil Production in 2007, MPOC, 2007.

[3] N. E. G. Frank, M. M. E. Albert, D. E. E. Laverdure, and K. Paul, "Assessment of the quality of crude palm oil from smallholders in Cameroon," Journal of Stored Products and Postharvest Research, vol. 2, no. 3, pp. 52-58, 2011.

[4] A. B. Nasrin, A. N. Ma, Y. M. Choo et al., "Oil palm biomass as potential substitution raw material from commercial biomass briquettes production," American Journal of Applied Sciences, vol. 5, no. 3, pp. 2404-2421, 2008.
[5] G. Anli, "Conversion of oil palm empty fruit bunch to biofuels," in Liquid, Gaseous and Solid Biofuels-Conversion Techniques, chapter 16, InTech, Rijeka, Croatia, 2013.

[6] K. W. Chan, I. Watson, and K. C. Um, "Use of oil palm waste material for increased production," in Proceedings of the Conference on Soil Science and Agricultural Development in Malaysia, E. Pushparajah and S. L. Chin, Eds., pp. 213-241, Malaysian Society of Soil Science, Kuala Lumpur, Malaysia, 1981.

[7] J. A. García-Núñez, M. García-Pérez, and K. C. Das, "Determination of kinetic parameters of thermal degradation of palm oil mill by-products using thermogravimetric analysis and differential scanning calorimetry," Transactions of the ASABE, vol. 51, no. 2, pp. 547-557, 2008.

[8] T. L. Chew and S. Bhatia, "Catalytic processes towards the production of biofuels in a palm oil and oil palm biomass-based biorefinery," Bioresource Technology, vol. 99, no. 17, pp. 79117922, 2008

[9] M. M. Ishola, R. Millati, S. Syamsiah, M. N. Cahyanto, C. Niklasson, and M. J. Taherzadeh, "Structural changes of oil palm empty fruit bunch (OPEFB) after fungal and phosphoric acid pretreatment," Molecules, vol. 17, no. 12, pp. 14995-15012, 2012.

[10] F. Ahmad, F. Bateni, M. S. Tavana, and A. S. Yahaya, Application of Thermoplastics in Protection of Natural Fibres, Thermoplastic Elastomers, P. A. El-Sonbati, Ed., InTech, 2012.

[11] M. J. John and S. Thomas, "Biofibres and biocomposites," Carbohydrate Polymers, vol. 71, no. 3, pp. 343-364, 2008.

[12] T. Y. Ying, L. K. Teong, W. N. Abdullah, and L. C. Peng, "The effect of various pretreatment methods on oil palm empty fruit bunch (EFB) and kenaf core fibers for sugar production," Procedia Environmental Sciences, vol. 20, pp. 328-335, 2014.

[13] R. N. Nkongho, Y. Nchanji, O. Tataw, and P. Levang, "Less oil but more money! Artisanal palm oil milling in Cameroon," African Journal of Agricultural Research, vol. 9, no. 20, pp. 1586-1596, 2014.

[14] K. Poku, Small-Scale Palm Oil Processing in Africa, FAO Agricultural Services Bulletin, FAO, Rome, Italy, 2002.

[15] J. C. Igwe and C. C. Onyegbado, "A review of palm oil mill effluent (Pome) water treatment," Global Journal of Environmental Research, vol. 1, no. 2, pp. 54-62, 2007.

[16] K. Wang, J. X. Jiang, F. Xu, and R. C. Sun, "Influence of steaming pressure on steam explosion pretreatment of Lespedeza stalks (Lespedeza crytobotrya): part 1. Characteristics of degraded cellulose," Polymer Degradation and Stability, vol. 94, no. 9, pp. 1379-1388, 2009. 
[17] M. Jacob, S. Thomas, and K. T. Varughese, "Mechanical properties of sisal/oil palm hybrid fiber reinforced natural rubber composites,' Composites Science and Technology, vol. 64, no. 7-8, pp. 955-965, 2004.

[18] M. S. Sreekala, J. George, M. G. Kumaran, and S. Thomas, "Water-sorption kinetics in oil palm fibers," Journal of Polymer Science, Part B: Polymer Physics, vol. 39, no. 11, pp. 1215-1223, 2001.

[19] M. S. Sreekala, M. G. Kumaran, and S. Thomas, "Oil palm fibers: morphology, chemical composition, surface modification, and mechanical properties," Journal of Applied Polymer Science, vol. 66, no. 5, pp. 821-835, 1997.

[20] H. J. William, P. Olivia, P. H. Immanuella, and T. Juliana, "Oil palm (Elaeis guineensis Jacq.) bunch structure variation and limitations," Scientific Research Journal, vol. 3, no. 1, pp. 5-10, 2015.

[21] N. Blumenkrantz and G. Asboe Hansen, "New method for quantitative determination of uronic acids," Analytical Biochemistry, vol. 54, no. 2, pp. 484-489, 1973.

[22] S. T. N. Rodrigue, "Mechanical characterization of bamboo filaments of raffia," in Mechanical Engineering, ENSP, Yaounde, Cameroon, 2008.

[23] J. Benton, J. Jones, and W. V. Case, "Sampling, handling and analyzing plant tissue samples," in Soil Testing and Plant Analysis, R. L. Westerman, Ed., Soil Science Society of America, 1990.

[24] A. Buondonno, A. A. Rashad, and E. Coppola, "Comparing tests for soil fertility II. The hydrogen peroxide/sulfuric acid treatment as an alternative to the copper/selenium catalyzed digestion process for routine determination of soil nitrogenKjeldahl," Communications in Soil Science \& Plant Analysis, vol. 26, no. 9-10, pp. 1607-1619, 1995.

[25] J. M. Anderson and J. S. I. Ingram, Tropical Soil Biology and Fertility: A Handbook of Methods, CAB International, The Cambrian News, Aberstwyth, UK, 2nd edition, 1993.

[26] M. Khalid, C. T. Ratnam, C. A. Luqman, A. Salmiaton, T. S. Y. Choong, and H. Jalaludin, "Thermal and dynamic mechanical behavior of cellulose- and Oil Palm Empty Fruit Bunch (OPEFB)-filled polypropylene biocomposites," Polymer-Plastics Technology and Engineering, vol. 48, no. 12, pp. 1244-1251, 2009.

[27] R. W. Scott and P. Gifford, "Influence of cations on the alkaline extraction of Xylan and glucomannan from pine pulps," Journal of Applied Polymer Science, vol. 38, pp. 907-914, 1989.

[28] B.-L. Xue, J.-L. Wen, F. Xu, and R.-C. Sun, "Structural characterization of hemicelluloses fractionated by graded ethanol precipitation from Pinus yunnanensis," Carbohydrate Research, vol. 352, pp. 159-165, 2012.

[29] P. Ramadevi, D. Sampathkumar, C. V. Srinivasa, and B. Bennehalli, "Effect of alkali treatment on the water absorption of single cellulosic abaca fiber," Bioresources, vol. 7, no. 3, pp. 35153524, 2012.

[30] H. P. S. A. Khalil, H. Ismail, H. D. Rozman, and M. N. Ahmad, "The effect of acetylation on interfacial shear strength between plant fibres and various matrices," The European Polymer Journal, vol. 37, no. 5, pp. 1037-1045, 2001.

[31] G. A. Bernabé, S. Almeida, C. A. Ribeiro, and M. S. Crespi, "Evaluation of organic molecules originated during composting process," Journal of Thermal Analysis and Calorimetry, vol. 106, no. 3, pp. 773-778, 2011.

[32] A. K. Bledzki and J. Gassan, "Composites reinforced with cellulose based fibres," Progress in Polymer Science, vol. 24, no. 2, pp. 221-274, 1999.
[33] A. Alemdar and M. Sain, "Isolation and characterization of nanofibers from agricultural residues-wheat straw and soy hulls," Bioresource Technology, vol. 99, no. 6, pp. 1664-1671, 2008.

[34] N. S. H. M. Yunos, A. S. Baharuddin, K. F. M. Yunos, M. N. Naim, and H. Nishida, "Physicochemical property changes of oil palm mesocarp fibers treated with high-pressure steam," BioResources, vol. 7, no. 4, pp. 5983-5994, 2012.

[35] W. A. W. Razali, A. S. Baharuddin, A. TarmezeeTalib et al., "Degradation of oil palm empty fruit bunches (OPEFB) fibre during composting process using in-vessel composter," BioResources, vol. 7, no. 4, pp. 4786-4805, 2012.

[36] M. Jonoobi, A. Khazaeian, P. M. Tahir, S. S. Azry, and K. Oksman, "Characteristics of cellulose nanofibers isolated from rubberwood and empty fruit bunches of oil palm using chemomechanical process," Cellulose, vol. 18, no. 4, pp. 1085-1095, 2011.

[37] K.-N. Law, W. R. W. Daud, and A. Ghazali, "Morphological and chemical nature of fiber strands of oil palm empty-fruit-bunch (OPEFB)," BioResources, vol. 2, no. 3, pp. 351-362, 2007.

[38] K. Nisizawa, "Mode of action of celluloses," Journal of Fermentation Technology, vol. 51, pp. 267-304, 1973.

[39] C. M. O. Müller, J. B. Laurindo, and F. Yamashita, "Effect of cellulose fibers on the crystallinity and mechanical properties of starch-based films at different relative humidity values," Carbohydrate Polymers, vol. 77, no. 2, pp. 293-299, 2009.

[40] D. V. Parikh, D. P. Thibodeaux, and B. Condon, "X-ray crystallinity of bleached and crosslinked cottons," Textile Research Journal, vol. 77, no. 8, pp. 612-616, 2007.

[41] S. Park, J. O. Baker, M. E. Himmel, P. A. Parilla, and D. K. Johnson, "Cellulose crystallinity index: measurement techniques and their impact on interpreting cellulase performance," Biotechnology for Biofuels, vol. 3, article 10, 2010.

[42] L. Segal, J. Creely, A. Martin, and C. Conrad, "An empirical method for estimating the degree of crystallinity of native cellulose using the x-ray diffractometer," Textile Research Journal, vol. 29, no. 10, pp. 786-794, 1959. 

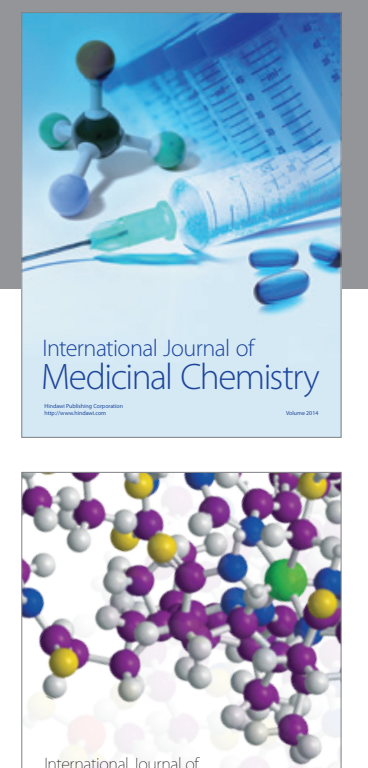

\section{Carbohydrate} Chemistry

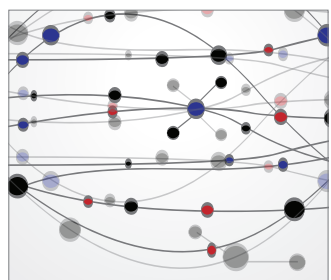

The Scientific World Journal
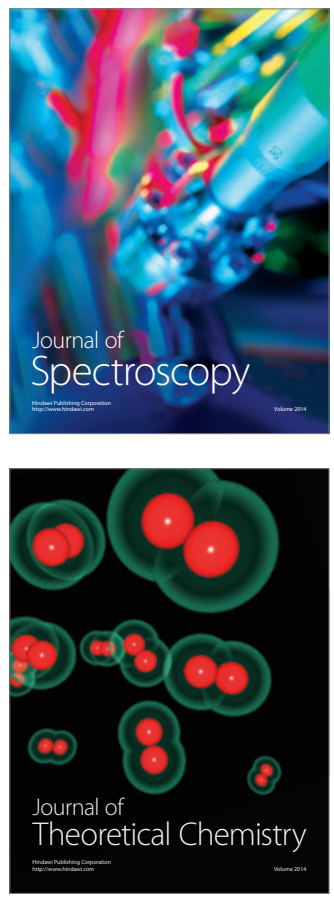
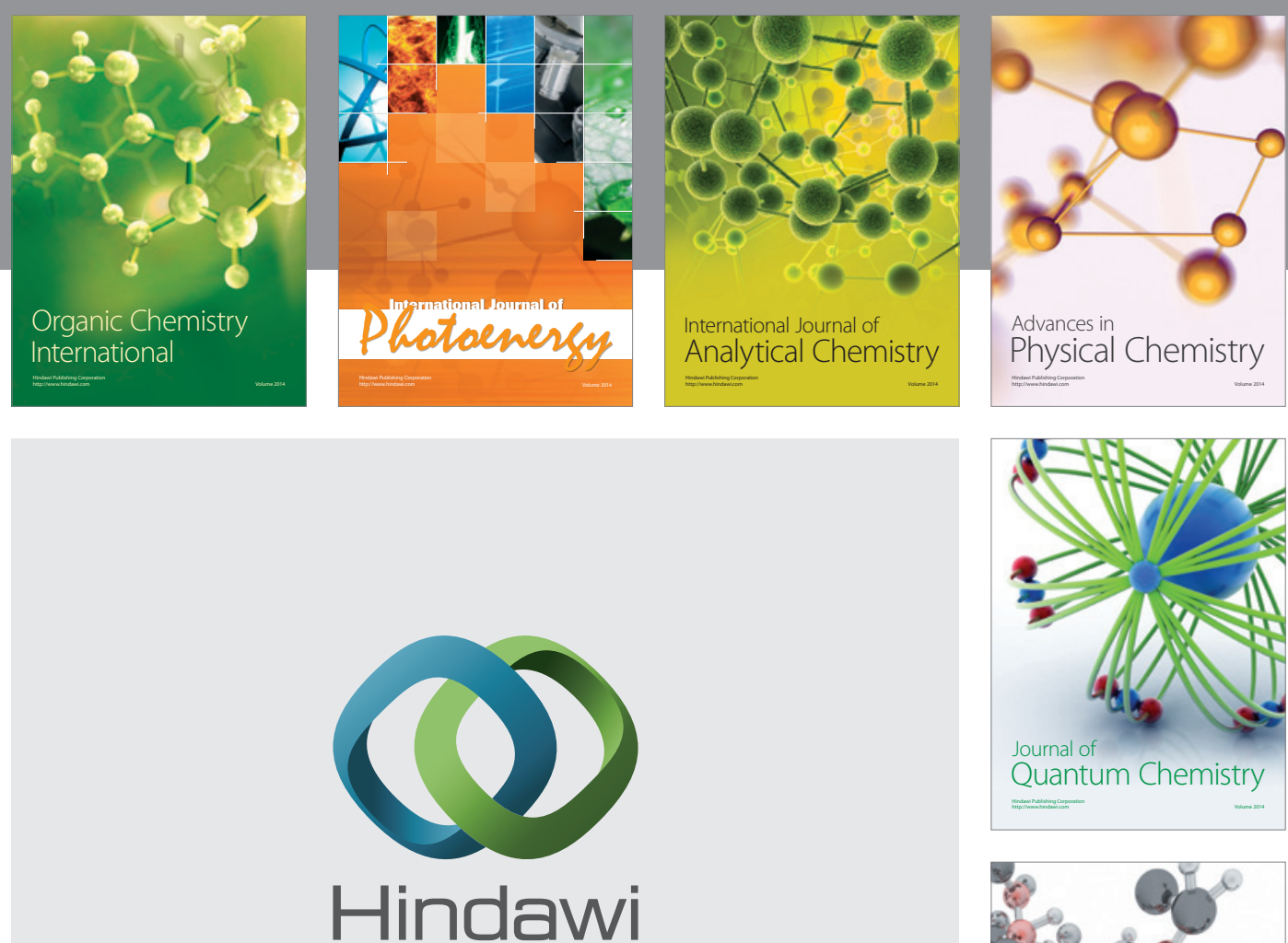

Submit your manuscripts at

http://www.hindawi.com

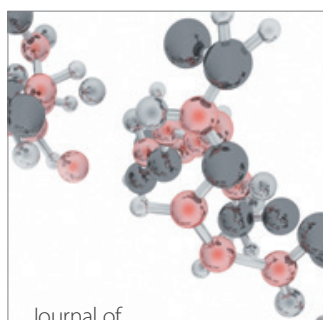

Analytical Methods

in Chemistry

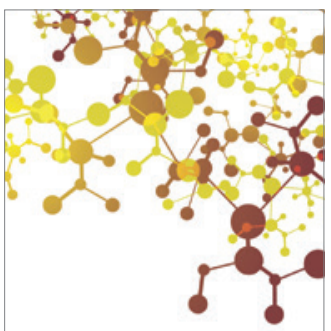

Journal of

Applied Chemistry

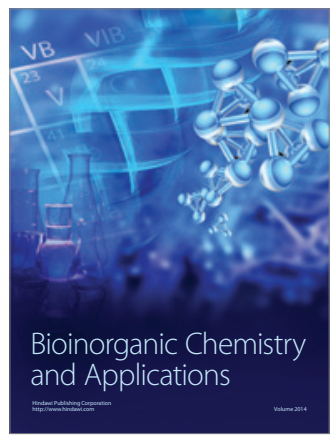

Inorganic Chemistry
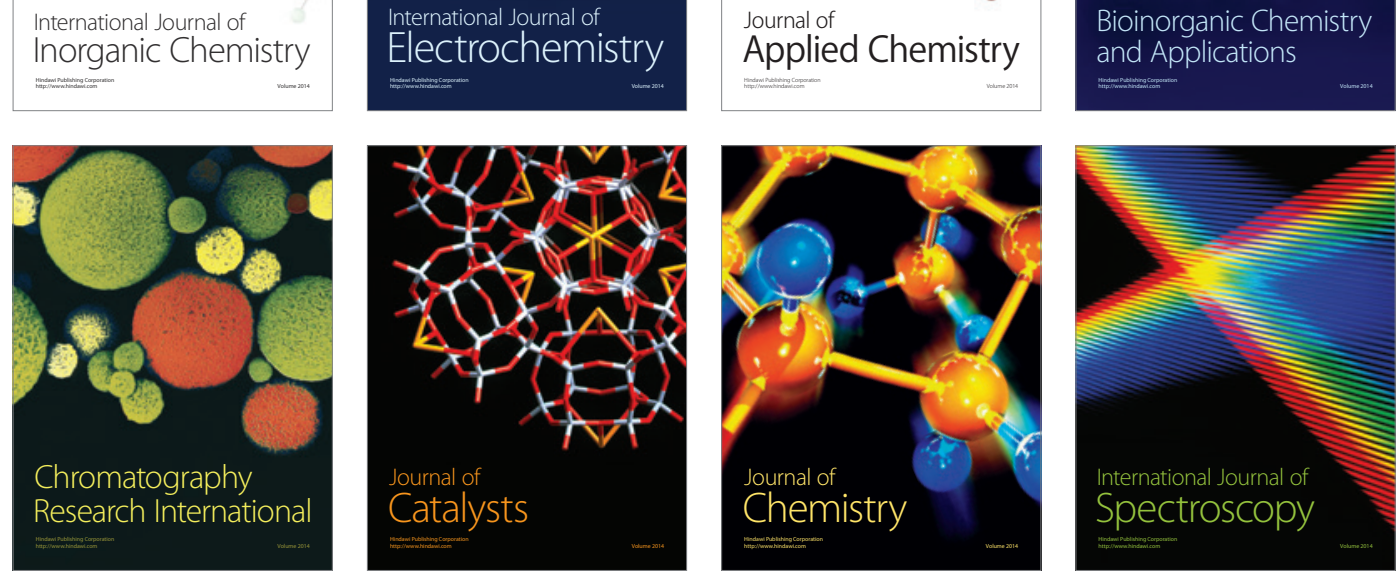